\title{
FINITE ELEMENT BASED THERMAL MODELING OF FRICTION WELDING OF DISSIMILAR MATERIALS
}

\author{
N. RAJESH JESUDOSS HYNES \\ Assistant Professor, Department of Mechanical Engineering, \\ Mepco Schlenk Engineering College, Sivakasi, Tamil Nadu 626005, India \\ findhynes@yahoo.co.in \\ P. NAGARAJ \\ Professor \& Head, Department of Mechanical Engineering, \\ Mepco Schlenk Engineering College, Sivakasi, Tamil Nadu 626005, India \\ nithyanraj@yahoo.com \\ R. MEBY SELVARAJ \\ II year M.E. CAD/CAM PG Student \\ Department of Mechanical Engineering, \\ Mepco Schlenk Engineering College, Sivakasi, Tamil Nadu 626005, India \\ mebyselvaraj@gmail.com
}

\begin{abstract}
Friction welding is a solid state joining process of joining either similar or dissimilar materials Joining of ceramic/metal joints by friction welding has opened up new possibilities in many engineering applications.In the present work, thermal modeling of friction welding process has been carried out. Using Finite Element Approach (FEA), analytical solutions were arrived for different ceramic/metal combinations. The temperature distributions of cylindrical surfaces of the alumina and the metals are found by means of 1D heat transfer assumption considering the effect of convection. In the thermal analysis, interfacial temperature and thermal conductivity of the material play a significant role. Based on the obtained temperature distribution the graphs are plotted between the length of the joint and the temperatures. Thus the knowledge of the temperature joint distribution could be helpful in predicting the thermal cycle of the process, microstructure evolution and residual stress formation. Thus the obtained graph helps to study and predict the temperature distribution of both the materials.
\end{abstract}

Keywords: ceramic-metals; temperature distribution; Finite Element Analysis.

\section{Introduction}

Welding of metals and ceramics materials gives new possibilities of applications due to the fact that both materials have significantly different physical, chemical and mechanical properties ${ }^{[1]}$. The ceramic materials have good elevated temperature resistance, strength and resistance to corrosion and wear which helps to use it for many fields of electronic, aerospace, nuclear and automotive industries ${ }^{[2]}$.

Friction welding is a solid state welding technology with good quality and reliability. In friction welding process, the temperature field, the stress field and the strain field are the three important factors, which directly affect the quality of welded joint ${ }^{[3]}$. 
During friction welding the heat is highly concentrated at the interface, so as a result the weld has a very narrow heat-affected zone (HAZ) which limits the variations in mechanical properties of the base metal to a small region ${ }^{[4]}$.

Instead of single piece ceramic component, joining of such materials is often preferred. Metal-ceramic joints become more important in modern technology because they combine the properties of metals like ductility and high electrical and thermal conductivity, and the properties of ceramics such as high hardness, corrosion and wear resistance. The main problem in the friction welding of dissimilar materials are not only associated with the individual properties but also by means of reactions that take place at the interface. Metals in general have a higher thermal expansion coefficient than ceramics. Therefore, when joining ceramics to metals using friction welding, very large thermal stresses will be induced and in many cases these large stresses cause joint failures. In order to overcome this problem solid phase bonding processes have been developed in which a metallic or a composite metal-ceramic interlayer is placed between the ceramic and metal surface to be joined ${ }^{[2]}$.

Mohamadet.al. ${ }^{[5]}$ welded the alumina rod and a mild steel rod by means of friction welding using an Al 1100 sheet as an interlayer. Jolantaet. al. ${ }^{[2]}$ modeled the elasticplastic metals. They successfully welded the corundum ceramic of 97.5\% of $\mathrm{Al}_{2} \mathrm{O}_{3}$ content with aluminum alloy 6061-T6 and electrolytic copper of $99.9 \% \mathrm{Cu}$. The simulation of the process is performed by means of finite element method using two FEM systems, namely ADINA-T and ADINA.

In joining of ceramics with metals, a detailed thermal analysis has to be carried in order to predict joint efficiency and Heat Affected Zone (HAZ). Hence, in the present work temperature distribution has been modeled using finite element approach for various ceramic/metal combinations.

\section{Experimentation}

In the experimentation done by Jolanta et al. ${ }^{[2]}$, cylindrical work pieces of $10 \mathrm{~mm}$ diameter of $97.5 \%$ alumina (corundum ceramics) had been chosen. In a friction welding machine, the ceramics was welded with aluminum alloy 6061-T6 having the same diameter.

Based on these parameters experimental runs were carried out. During welding process measurement was carried out by means of thermo vision on line temperature measurement setup.

In the temperature profile, the peak temperature at the weld interface was found to be $320^{\circ} \mathrm{C}$ during experimentation ${ }^{[2]}$. Hence this peak temperature at the interface has been given as a valid input in the present thermal modeling.

\section{Thermal Modeling}

In the present work thermal modeling of friction welding process is based on Fourier's heat conduction equations in which ceramics and metal volumes were as follows:

$$
\frac{\delta}{\delta x}\left(\mathrm{k} \frac{\delta T}{\delta x}\right)+\frac{\delta}{\delta y}\left(\mathrm{k} \frac{\delta T}{\delta y}\right)+\frac{\delta}{\delta z}\left(\mathrm{k} \frac{\delta T}{\delta z}\right)=\frac{\delta T}{\delta t}
$$


Here the material 1 is considered as the ceramic material of alumina. Owing to the applications, different metals such as Aluminum, Aluminum Alloy 6063, Stainless steel AISI 304 and Mild Steel had been selected as Material 2

\subsection{Assumptions}

- The model is considered to be a one dimensional.

- No heat transfer at the end face of the ceramics and metals

- Radiation effect is negligible and so radiation loss is not considered

- Heat flux is omitted and the interface temperature is assumed as $500 \mathrm{~K}$

convection

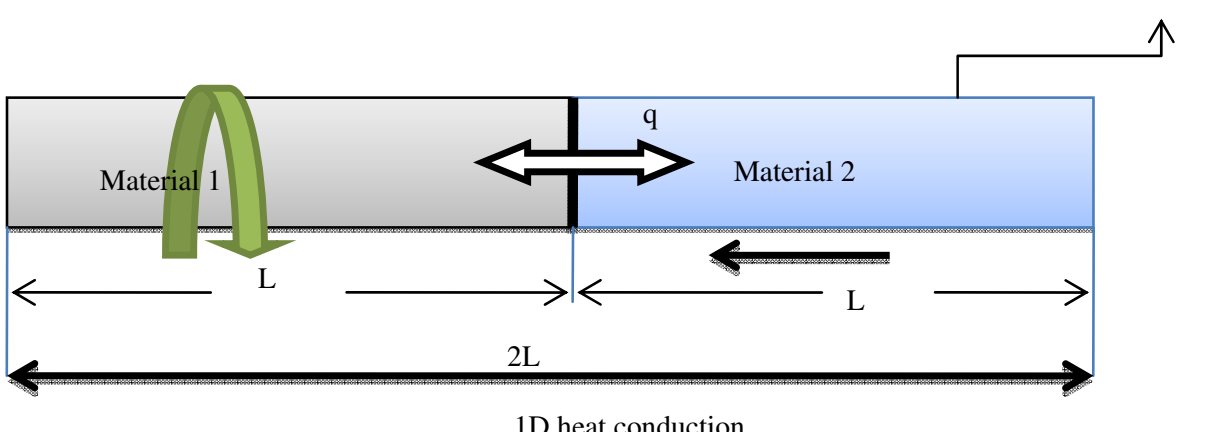

Where $\mathrm{q}$ is heat generated at the interface

Fig 1: Numerical model

\subsection{Boundary Conditions}

- Heat flux (q) intensity at the medium boundary was calculated as

$$
\mathrm{q}=\mathrm{q}_{\text {ceramics }}+\mathrm{q}_{\text {metals }}=\mu \mathrm{P}_{\mathrm{n}} \omega \mathrm{r}
$$

- Lateral surfaces $S_{\text {ceramics }}$ and $S_{\text {metals }}$ transferred heat into surroundings which were based on the principle of convection exchange. This flux was as follows:

$$
\begin{aligned}
& \mathrm{q} \mid \mathrm{S}_{\text {ceramics }}=\mathrm{h}_{\text {ceramics }}\left(\mathrm{T}_{\text {ceramics }}-\mathrm{T}^{0}\right) \\
& \mathrm{q} \mid \mathrm{S}_{\text {metals }}=\mathrm{h}_{\text {metals }}\left(\mathrm{T}_{\text {metals }}-\mathrm{T}^{0}\right)
\end{aligned}
$$

- The problem of heat conduction in the process of friction welding determined by means of these equations.

\section{Finite Element Approach (FEA)}

For a one-dimensional heat transfer problem, the governing differential equation is given by

$$
\mathrm{k} \frac{d^{2} T}{d x^{2}}+\dot{q}=0
$$


The boundary conditions are

$$
\begin{aligned}
& \mathrm{T}(\mathrm{x}=0)=\mathrm{T}_{0} \text { (temperature specified) } \\
& \mathrm{k} \frac{d T}{d x} l_{x}+\mathrm{h}\left(\mathrm{T}-T_{\infty}\right)+\mathrm{q}=0 \text { on the surface }
\end{aligned}
$$

The steps involved in solving the one-dimensional heat transfer problem with convection loss is given by

Step 1: Idealize the rod into several finite elements

Step 2: Assume a linear temperature variation inside any element "e" as

$$
\begin{aligned}
& T^{(e)}(\mathrm{x})=\mathrm{a} l+\mathrm{a} 2 \mathrm{x}=[\mathrm{N}(\mathrm{x})] \vec{q}^{(e)} \\
& {[\mathrm{N}(\mathrm{x})]=\left[\begin{array}{ll}
\mathrm{N}_{\mathrm{i}}(\mathrm{x}) & \mathrm{N}_{\mathrm{j}}(\mathrm{x})
\end{array}\right]} \\
& \vec{q}^{(e)}=\left[\begin{array}{c}
\mathrm{T}_{1} \\
T_{2}
\end{array}\right]=\left[\begin{array}{c}
q_{1} \\
q_{2}
\end{array}\right]
\end{aligned}
$$

$\mathrm{i}$ and $\mathrm{j}$ indicate the global node numbers corresponding to the left- and righthand-side nodes, and $l^{(e)}$ is the length of element e.

Step 3: Derivation of element matrices: Since this is a one-dimensional problem reduce to

$$
\begin{aligned}
& {[\mathrm{D}]=[\mathrm{k}] \text { and }[\mathrm{B}]=\left[\frac{\partial N i}{\partial x} \frac{\partial N j}{\partial x}\right]=\left[-\frac{1}{l^{(e)}} \frac{1}{l^{(e)}}\right]} \\
& {\left[\mathrm{K}_{1}^{(e)}\right]=\frac{A k}{l^{e}}\left[\begin{array}{cc}
1 & -1 \\
-1 & 1
\end{array}\right]} \\
& {\left[\mathrm{K}_{2}^{(e)}\right]=\frac{h P l^{(e)}}{6}\left[\begin{array}{ll}
2 & 1 \\
1 & 2
\end{array}\right]}
\end{aligned}
$$

Since $d S_{3}=P d x$, where $P$ is the perimeter.

$\left[\mathrm{K}_{3}{ }^{(e)}\right]=[0]$ since this is a steady-state problem

$$
\vec{P}^{(e)}=\frac{q \dot{A} l^{e}}{2}\left\{\begin{array}{l}
1 \\
1
\end{array}\right\}-\frac{q P l^{e}}{2}\left\{\begin{array}{l}
1 \\
1
\end{array}\right\}-\frac{h T_{\infty} P l^{e}}{2}\left\{\begin{array}{l}
1 \\
1
\end{array}\right\}
$$

Step 4: Assembled equations: The element matrices can be assembled to obtain the overall equations as

$$
[\mathrm{K}] \vec{T}=\vec{P}
$$

Where

$$
[\mathrm{K}]=\sum_{e=1}^{E}\left(\frac{A k}{l^{e}}\left[\begin{array}{cc}
1 & -1 \\
-1 & 1
\end{array}\right]+\frac{h P l^{(e)}}{6}\left[\begin{array}{ll}
2 & 1 \\
1 & 2
\end{array}\right]\right)
$$




$$
\vec{P}=\sum_{e=1}^{E} \vec{P}^{e}=\sum_{e=1}^{E} \frac{1}{2}\left(q A l^{e}-q P l^{e}+h T_{\infty} P l^{e}\right)\left\{\begin{array}{l}
1 \\
1
\end{array}\right\}
$$

Step 5: The assembled equations (11) are to be solved, after incorporating the boundary conditions stated in (2) to find the nodal temperatures.

\subsection{For convection}

The following method can be adopted. Let the convection heat loss occur from the surface at the right-hand-side node of the element e. Then the surface integral (11) of should extend over this surface also. Thus, in equation (11) the following term should also be included:

$$
\iint_{S_{3}^{e}} h[N]^{T}[N] d S_{3}=\iint_{A} h\left\{\begin{array}{l}
N_{1} \\
N_{2}
\end{array}\right\}\left\{N_{1} N_{2}\right\} \mathrm{d} S_{3}
$$

Corresponding the surface at the right-side node 2.

Since we are interested in the surface at node 2 (right-side node), we substitute N1 $\left(\mathrm{x}=l^{(e)}\right)=0$ and $\mathrm{N} 2\left(\mathrm{x}=l^{(e)}\right)=1$ in eq $(15)$ to obtain

$$
\iint_{A} h\left\{\begin{array}{l}
0 \\
1
\end{array}\right\}\left\{\begin{array}{ll}
0 & 1
\end{array}\right\} \mathrm{d} S_{3}=\iint_{A} h\left[\begin{array}{ll}
0 & 0 \\
0 & 1
\end{array}\right] \mathrm{d} S_{3}=\mathrm{hA}\left[\begin{array}{ll}
0 & 0 \\
0 & 1
\end{array}\right]
$$

Similarly, the surface integral over S3 in equation (13) should extend over the free end surface also. Thus, the additional term to be included in the vector $\vec{P}^{(e)}$ is given by

$$
\iint_{S_{3}^{e}} h T_{\infty}[N]^{T} d S_{3}=\mathrm{h} T_{\infty} \iint_{A}\left\{\begin{array}{l}
0 \\
1
\end{array}\right\} \mathrm{d} S_{3}=\mathrm{h} T_{\infty} \mathrm{A}\left\{\begin{array}{l}
0 \\
1
\end{array}\right\}
$$

In this the materials are divided into two elements ie. 3 nodes. Also $T_{1}$ is constant of 500 $\mathrm{K}$ for all the materials which is the temperature of the interface. Then by means of finite element approach the other two temperatures $T_{2} T_{4}$ are calculated. Then the temperature $\mathrm{T}_{3}$ is calculated by means of interpolation. The interpolation formula is given by

$$
y_{2=\frac{\left(x_{2}-x_{1}\right)\left(y_{3}-y_{1}\right)}{\left(x_{3}-x_{1}\right)}}+y_{1}
$$

Thus the temperature $T_{3}$ is calculated. These steps and its assumptions are to be considered for material 2 also. This step is repeated to calculate for all the materials.

\section{Results and Discussion}

In Fig $2 \& 3$ the temperature distribution of alumina and aluminum alloy 6063 and temperature distribution of alumina and aluminum are shown respectively. In both the cases, steep decrease in temperature on alumina side is evident that can be attributed to lower value of thermal conductivity of alumina $(30 \mathrm{~W} / \mathrm{mK})$. The thermal conductivity of aluminum and aluminum alloy 6063 are $240 \mathrm{~W} / \mathrm{mK}$ and $200 \mathrm{~W} / \mathrm{mK}$ respectively. Hence similar has been observed in Fig $2 \& 3$. 


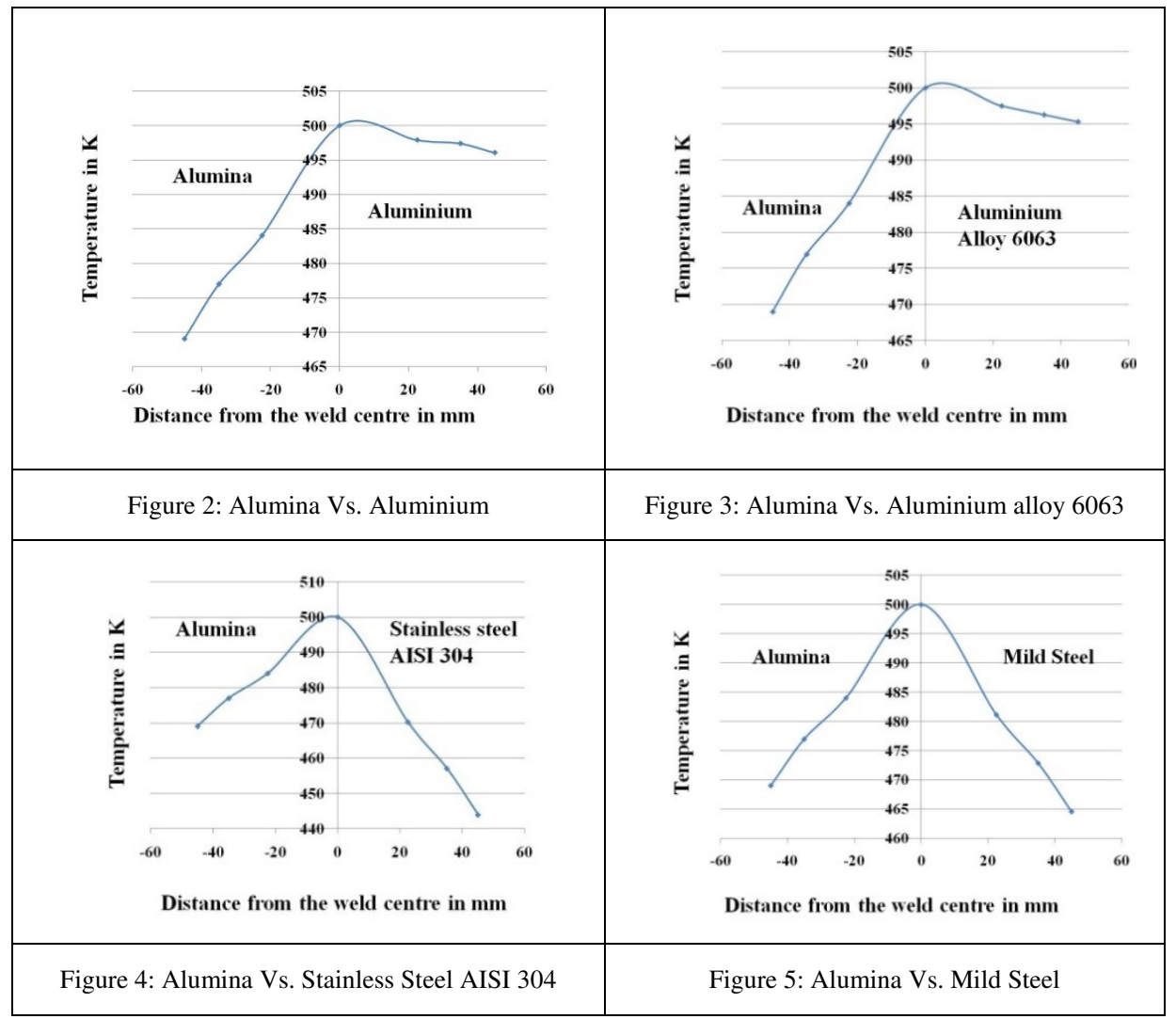

The thermal conductivity of mild steel is $23 \mathrm{~W} / \mathrm{mK}$ which is very near to alumina (30w/mK). Hence, in Fig 4, similar steep decrease is found on both alumina side and mild steel side. The thermal conductivity of stainless steel is $16.2 \mathrm{~W} / \mathrm{mK}$ approximately half of that of alumina. Since, the thermal conductivity of stain less steel is lesser than alumina; the curve is steeper than stainless steel than alumina.

\section{Conclusion}

Joining of ceramics with metals opens up new possibilities in many engineering applications. But in actual practice it is difficult and challenging. Thermal modeling using Finite Element approach helps to stimulate the temperature distribution of dissimilar joints during the friction welding process. In the present work using Finite Element analysis technique, temperature distribution of various combinations such as Alumina-Aluminum, Alumina -Aluminum Alloy 6063, Alumina- Stainless Steel AISI 304, Alumina-Mild steel are plotted against the length of the joints. Knowledge of thermal distribution could be used as a tool to predicting heat affected zone and microstructural evaluation. 


\section{References}

1. C.J Bennett, T.H Hyde, P.H Shipway, J. Computational Material Science. 50, 2592-2598 (2011).

2. JolantaZimmerman,WladyslawWlosinski, ZdzislawR.Lindemann, J. Material Processing Technology. 209, 1644-1653 (2009).

3. Z.Lindemann, K. Skalski, W.Wlosinski and J.Zimmerman, Thermo-mechanical phenomena in the process of friction welding of corundum ceramics and aluminum. (Science Direct Vol.54 No.1 2006).

4. C.M Chen, R. Kovacevic, J. Machine tools \& manufacture43, 1319-1326 (2003).

5. MohamadZaky Noh, LuayBakirHussain, ZainalArifin Ahmad, J. Material Processing Technology. 204, 279-283 (2008).

6. M.B.Uday, M.N.AhmadFauzi, H.Zuhailawati, A.B.Iamail, Thermal analysis of friction welding process in relation to the welding of YSZ-alumina composite and 6061 aluminum alloy (Elsevier Malaysia 2012)

7. 1.W.Zhang, J.B Pei, Q.Z.Zhang, C.D.Liu, W.H.Zhu, S.Qu and J.H.Wang, The coupled FEM analysis of transient temperature field during inertia friction welding of GH4169 alloy.(Science Direct Vol.20 No.4 pp 301-306 Aug 2007)

8. O.T.Midling and O.Grong, A process model for friction welding of Al-Mg-Si alloys and Al-SiC metal matrix composites. HAZ temperature and strain rate distribution.(Pergamon Vol.42 No.5 pp 1595-1609, 1994) 